Check for updates

Cite this: Chem. Sci., 2019, 10, 4868

๑ All publication charges for this article have been paid for by the Royal Society of Chemistry

Received 29th January 2019

Accepted 3rd April 2019

DOI: $10.1039 / \mathrm{c} 9 \mathrm{sc} 00527 \mathrm{~g}$

rsc.li/chemical-science

\title{
Layered $\mathrm{Zn}_{2}\left[\mathrm{Co}(\mathrm{CN})_{6}\right]\left(\mathrm{CH}_{3} \mathrm{COO}\right)$ double metal cyanide: a two-dimensional DMC phase with excellent catalytic performance $\uparrow$
}

\author{
Carlos Marquez, (D) a Arkadiy Simonov, ${ }^{\mathrm{b}}$ Michael T. Wharmby, (DD ${ }^{\mathrm{c}}$ Cédric Van \\ Goethem, (D) a Ivo Vankelecom, (D) ${ }^{a}$ Bart Bueken, (D) ${ }^{a}$ Andraž Krajnc, ${ }^{d}$ Gregor Mali, (D) d \\ Dirk De Vos ${ }^{* a}$ and Trees De Baerdemaeker (D)*a
}

\begin{abstract}
Double metal cyanides (DMCs) are well known, industrially applied catalysts for ring opening polymerization reactions. In recent years, they have been studied for a variety of catalytic reactions, as well as other applications, such as energy storage and Cs sorption. Herein, a new, layered DMC phase (L-DMC), $\mathrm{Zn}_{2}\left[\mathrm{Co}(\mathrm{CN})_{6}\right]\left(\mathrm{CH}_{3} \mathrm{COO}\right) \cdot 4 \mathrm{H}_{2} \mathrm{O}$, was synthesized. The structure, which crystallizes in the monoclinic space group $P 2_{1} / m$, consists of positively charged $\left\{\mathrm{Zn}_{2} \mathrm{Co}(\mathrm{CN})_{6}\right\}^{+} \mathrm{DMC}$ layers linked through acetate groups and presents a new layered structure to the family of double metal cyanides. L-DMC proved to be a reusable and stable catalyst that exhibited a higher activity than the benchmark DMC catalyst in two important applications: hydroamination of phenylacetylene with 4-isopropylaniline and polymerization of 1,2-epoxyhexane.
\end{abstract}

\section{Introduction}

Double metal cyanides (DMCs) are inorganic coordination polymers containing two metal atoms connected by cyanide groups. They have been used industrially as solid catalysts for the ring opening polymerization of epoxides since the $1960 \mathrm{~s},{ }^{1-3}$ and their potential as Lewis acid catalysts for other organic transformations such as co-polymerization of epoxides and $\mathrm{CO}_{2}{ }^{4,5}$ hydroamination, ${ }^{6-8}$ transesterification ${ }^{9}$ and coupling reactions $\mathrm{s}^{\mathbf{1 0 , 1 1}}$ has recently been uncovered. DMCs can generally be described as polynuclear transition metal cyanides with the structural formula $\mathrm{M}_{u}\left[\mathrm{M}^{\prime}(\mathrm{CN})_{n}\right]_{v} \cdot x \mathrm{H}_{2} \mathrm{O}$ (M and $\mathrm{M}^{\prime}$ are two metal cations), which often crystallize with a cubic unit cell. ${ }^{12}$ The common $u-v$ combination 3-2 can be described as a rock salt type structure consisting of alternating $\mathrm{M}^{2+}$ and $\left[\mathrm{M}^{\prime}(\mathrm{CN})_{6}\right]^{3-}$

${ }^{a}$ Centre for Surface Chemistry and Catalysis, KU Leuven, Celestijnenlaan 200F, 3001 Leuven, Belgium. E-mail: dirk.devos@kuleuven.be; trees.debaerdemaeker@kuleuven. be

${ }^{b}$ Inorganic Chemistry Laboratory, University of Oxford, South Parks Road, Oxford OX1 $3 Q R, U K$

${ }^{c}$ Deutsches Elektronen-Synchrotron (DESY), Notkestraße 85, 22607 Hamburg, Germany

${ }^{d}$ Department of Inorganic Chemistry and Technology, National Institute of Chemistry, Hajdrihova 19, 1001 Ljubljana, Slovenia

$\dagger$ Electronic supplementary information (ESI) available: Characterization (XRD patterns, SEM and TEM images, $\mathrm{N}_{2}$ sorption isotherms, FTIR spectra, ${ }^{1} \mathrm{H}$ MAS NMR spectra, TG-MS profiles) of the synthesized DMCs and L-DMC and catalytic data of the synthesized DMCs. Stability, recycling and hot filtration test of L-DMC. CCDC 1894386. For ESI and crystallographic data in CIF or other electronic format see DOI: $10.1039 / \mathrm{c} 9 \mathrm{sc} 00527 \mathrm{~g}$ ions. The charge imbalance between these ions produces vacancies that occur at one in three $\left[\mathrm{M}^{\prime}(\mathrm{CN})_{6}\right]^{3-}$ sites. ${ }^{13-15}$ Even though the cubic phase is the most common, the occurrence of other phases, for example a monoclinic and a rhombohedral phase for $\mathrm{Zn}_{3}\left[\mathrm{Co}(\mathrm{CN})_{6}\right]_{2}$, has also been observed. ${ }^{16,17}$

In all the aforementioned phases, however, the pores are too narrow to allow the diffusion of the majority of aromatic compounds, which for DMC-catalyzed reactions of these molecules signifies that the reaction takes place on the outer surface. ${ }^{7}$ In the light of this, many strategies have been suggested in order to increase the accessibility and availability of the catalytically active sites. For example, we recently showed that by dispersing the catalytically active $\mathrm{Zn}_{3}\left[\mathrm{Co}(\mathrm{CN})_{6}\right]_{2} \mathrm{DMC}$ on silica, its activity can be vastly improved in hydroamination and epoxide polymerization reactions because of the increased accessibility of the active sites. ${ }^{8}$ Furthermore, Robertson et al. ${ }^{18}$ proposed layered $\mathrm{Co}\left(\mathrm{H}_{2} \mathrm{O}\right)_{2}\left[\mathrm{M}^{\prime}(\mathrm{CN})_{4}\right]$ DMCs $\left(\mathrm{M}^{\prime}=\mathrm{Ni}\right.$, Pd or Pt) as high surface area catalysts for the propylene oxide (PO) homopolymerization and $\mathrm{PO} / \mathrm{CO}_{2}$ copolymerization. In this case, the activity of the $\mathrm{Co}\left[\mathrm{M}^{\prime}(\mathrm{CN})_{4}\right]$ system still remained lower than that of the $\mathrm{Zn}_{3}\left[\mathrm{Co}(\mathrm{CN})_{6}\right]_{2}$ DMCs. Layered materials, such as layered double hydroxides (LDHs), layered metal-organic frameworks (MOFs) and clay minerals, are generally of wide interest because of their highly tunable properties and wide range of potential applications, including in catalysis, ${ }^{19-22}$ energy storage, ${ }^{23,24}$ and $\mathrm{CO}_{2}$ capture. ${ }^{25,26}$ Additionally, their potential for modification through, for instance, exfoliation has been extensively investigated in the case of clays, layered zeolite precursors or layered double hydroxides..$^{27-35}$ 
During our investigation of $\mathrm{Zn}_{3}\left[\mathrm{Co}(\mathrm{CN})_{6}\right]_{2}$ DMCs, we discovered single crystals of a phase that was not cubic, but instead, consisted of positively charged DMC layers linked by acetate anions. To the best of our knowledge, such a cationic, layered DMC structure has not yet been reported in the literature. Given the known catalytic activity of other $\mathrm{Zn}_{3}\left[\mathrm{Co}(\mathrm{CN})_{6}\right]_{2}$ DMCs - cubic, ${ }^{36}$ monoclinic, ${ }^{16}$ or (partially) amorphous ${ }^{37-39}$ - we were motivated to synthesize this layered DMC phase as a powder to investigate its catalytic properties. Herein, we report the synthesis, structure, physicochemical characterization and catalytic activity of this layered DMC (L-DMC). Moreover, the advantages of L-DMC over the benchmark DMC catalyst will be demonstrated for two important catalytic applications of DMCs: hydroamination of phenylacetylene and 4-isopropylaniline, and epoxide polymerization of 1,2-epoxyhexane.

\section{Experimental section}

\section{Synthesis of single-crystal L-DMC}

Single crystals of L-DMC were grown from silica gel using a modification of the technique reported in ref. 40 and 41 . The silica gel was formed by mixing $2.5 \mathrm{~mL}$ of a $1.37 \mathrm{M}$ aqueous solution of $\mathrm{Na}_{2} \mathrm{SiO}_{3}$ with $2.5 \mathrm{~mL}$ of a $0.0125 \mathrm{M}$ aqueous solution of zinc acetate dihydrate and $5 \mathrm{~mL}$ of an aqueous acetic acid solution ( $2 \mathrm{M})$, and leaving the solution to stand overnight. Subsequently, a $\mathrm{K}_{3}\left[\mathrm{Co}(\mathrm{CN})_{6}\right]$ solution $(3 \mathrm{~mL}, 0.0833 \mathrm{M})$ was layered on top of the gel and the crystals were left to grow for three days.

\section{Optimized synthesis of L-DMC (powder)}

Zinc acetate dihydrate $\left(\mathrm{Zn}\left(\mathrm{CH}_{3} \mathrm{COO}\right)_{2} \cdot 2 \mathrm{H}_{2} \mathrm{O}, 3 \mathrm{mmol}\right)$ was dissolved in $20 \mathrm{~mL}$ of a $4 \mathrm{M}$ solution of acetic acid. The solution was stirred and heated to $80{ }^{\circ} \mathrm{C}$ in an oil bath before dropwise addition of $10 \mathrm{~mL}$ of an aqueous solution containing $1.5 \mathrm{mmol}$ of $\mathrm{K}_{3}\left[\mathrm{Co}(\mathrm{CN})_{6}\right]$. The reaction was immediately removed from the bath and the precipitate was recovered by centrifugation, washed three times with distilled water and dried at $80^{\circ} \mathrm{C}$ under vacuum (587 $\mathrm{mg}, 82 \%$ yield).

\section{Synthesis of benchmark DMC (DMC-PTMEG)}

The benchmark DMC catalyst (DMC-PTMEG) was synthesized with tert-butanol $\left({ }^{t} \mathrm{BuOH}\right)$ as complexing agent and poly(tetramethylene ether)glycol (PTMEG) as co-complexing agent following literature procedures. ${ }^{6-8,42}$ This material has been reported to be the most active compared to other $\mathrm{Zn}_{3}\left[\mathrm{Co}(\mathrm{CN})_{6}\right]_{2}$ DMCs prepared by co-precipitation for intermolecular hydroamination of amines and alkenes or alkynes and ring opening polymerization reactions. ${ }^{6,42} \mathrm{ZnCl}_{2}(15 \mathrm{mmol})$ and PTMEG (1.5 mmol) were dissolved in $150 \mathrm{~mL}$ of water. To this, $15 \mathrm{~mL}$ of a $0.1 \mathrm{M}$ aqueous solution of $\mathrm{K}_{3}\left[\mathrm{Co}(\mathrm{CN})_{6}\right]$ was added dropwise. ${ }^{t} \mathrm{BuOH}(37.5 \mathrm{~mL})$ was added to the reaction mixture, which was subsequently stirred for $3 \mathrm{~h}$ at room temperature. The final solid was recovered by centrifugation and washed three times with a $50: 50$ mixture of water : ${ }^{t} \mathrm{BuOH}$, and then dried at $60{ }^{\circ} \mathrm{C}$ overnight.

\section{Characterization}

High-throughput powder X-ray diffraction (PXRD) data were recorded on a Malvern PANalytical Empyrean diffractometer equipped with a PIXcel3D solid state detector using a $\mathrm{Cu}$ anode $\left(\mathrm{CuK}_{\alpha 1,2}\right.$ radiation) in transmission geometry $\left(1.3-45^{\circ} 2 \theta\right.$ range; $0.013^{\circ}$ step size), or on a STOE Stadi MP diffractometer (in transmission mode) using an image plate detector and focusing $\mathrm{Ge}(111)$ monochromator $\left(\mathrm{CuK}_{\alpha 1}\right.$ radiation) over a range of $5-60^{\circ}$ $2 \theta$. All PXRD patterns were recorded at room temperature. Singlecrystal X-ray diffraction measurements were performed at beamline I19 (Diamond Light Source, Oxfordshire, UK) ${ }^{43}$ using a wavelength of $\lambda=0.6889 \AA$ with the crystal cooled to a temperature of $-173{ }^{\circ} \mathrm{C}$. The structure was solved using SUPERFLIP and refined using tools available within the Crystals and Olex2 suites. ${ }^{4-46}$ High-resolution synchrotron powder X-ray diffraction data were collected at beamline P02.1, PETRA III (DESY, Hamburg, Germany) at a wavelength of $\lambda=0.20738 \AA$ using a PerkinElmer area detector. ${ }^{47}$ The as-prepared L-DMC powder sample was loaded into a $0.5 \mathrm{~mm}$ borosilicate glass capillary tube and data were collected for $60 \mathrm{~s}$ in Debye-Scherrer geometry. Raw twodimensional detector images were integrated using the DAWN suite, using a bin size of $0.005^{\circ} 2 \theta .^{48}$ Indexing, Pawley fitting and Rietveld refinement of the powder diffraction data were performed using the routines of TOPAS-Academic V5 ${ }^{49-51}$ Chemically sensible restraints were applied to the $\mathrm{C}-\mathrm{N}, \mathrm{C}-\mathrm{C}, \mathrm{C}-\mathrm{O}, \mathrm{Co}-\mathrm{C}, \mathrm{Zn}-\mathrm{N}$ and $\mathrm{Zn}-\mathrm{O}$ distances. The metal ratio of the L-DMC was determined with ICP-OES using a Varian 720-ES equipped with a double-pass glass cyclonic spray chamber, a Sea Spray concentric glass nebulizer and a high solids torch. Samples were digested in a $7: 3(\mathrm{v}: \mathrm{v})$ solution of $\mathrm{HNO}_{3}-\mathrm{HCl}$ and heated to $200{ }^{\circ} \mathrm{C}$ in a microwave oven for $2 \mathrm{~h}$, as reported by Lee et al. ${ }^{52}$ Fouriertransform infrared (FTIR) spectra of $\mathrm{KBr}$ wafers (1 $\mathrm{wt} \%$ of DMC) were collected on a Bruker IFS 66 v/S Vacuum FTIR spectrometer (resolution $4 \mathrm{~cm}^{-1}$ ). Solid state nuclear magnetic resonance experiments (SSNMR) were performed on a $600 \mathrm{MHz}$ Varian spectrometer, equipped with a $1.6 \mathrm{~mm}$ triple-resonance magicangle spinning (MAS) probe. Larmor frequencies were 599.44 MHz for ${ }^{1} \mathrm{H}$ and $150.74 \mathrm{MHz}$ for ${ }^{13} \mathrm{C}$ nuclei, and the spectral axes of the recorded spectra were referenced with respect to the signals of tetramethylsilane. The sample was spun at MAS rate of $40 \mathrm{kHz}$. The ${ }^{1} \mathrm{H}$ MAS NMR spectrum was collected using Hahnecho sequence with $90^{\circ}$ and $180^{\circ}$ pulses of $1.5 \mu$ s and $3.0 \mu \mathrm{s}$, respectively, and inter-pulse delay of $25 \mu \mathrm{s} .16$ scans were accumulated with a recycle delay of $5 \mathrm{~s}$. The ${ }^{1} \mathrm{H}^{-13} \mathrm{C}$ cross-polarization (CP) MAS NMR spectrum was recorded by first exciting protons and transferring polarization to carbon nuclei using the rampedamplitude CP block with a duration of $5 \mathrm{~ms} .10000$ scans were accumulated with the recycle delay of $1 \mathrm{~s}$. During the acquisition, high-power XiX heteronuclear decoupling was applied. $\mathrm{N}_{2}$ physisorption isotherms were collected on a Micromeritics 3Flex Surface Analyzer at $-196{ }^{\circ} \mathrm{C}$. Before the measurements, the samples were evacuated at $150{ }^{\circ} \mathrm{C}$ for $16 \mathrm{~h}$. The specific surface area $\left(S_{\mathrm{BET}}\right)$ was determined using the BET method in a $p / p_{0}$ range from 0.004 to 0.03 . The specific external surface area $\left(S_{\mathrm{ext}}\right)$ and the micropore volume $\left(V_{\text {micro }}\right)$ were obtained using $t$-plot analysis. In order to estimate the micropore size distribution (MPSD), Ar 
physisorption isotherms were collected under similar conditions and the MPSD was estimated using the Horvath-Kawazoe (HK) method. Scanning electron microscopy (SEM) images were taken using a JEOL-6010LV SEM. Prior to imaging, samples were coated with a Pd/Au layer using a JEOL JFC-1300 autofine coater under Ar plasma for $10 \mathrm{~s}$. Transmission electron microscopy (TEM; high angle annular dark field, HAADF) images and energy-dispersive Xray spectroscopy (EDX) maps were recorded with a JEOL ARM$200 \mathrm{~F}$ TEM with a probe Cs corrector operated at $200 \mathrm{kV}$. Before imaging, the samples were suspended in ethanol and dropped onto a $\mathrm{Cu}$ grid (300 Mesh, Pacific Grid Tech, USA) coated with a Lacey carbon layer. Thermogravimetric mass spectrometry (TG-MS) analysis measurements were carried out on a NETZSCH STA 449 F3 Jupiter ${ }^{\circledR}$ thermal analyzer coupled with a Hiden HPR-20 EGA gas analysis system with a heating rate of $10{ }^{\circ} \mathrm{C} \min ^{-1}$ under air atmosphere.

\section{Catalytic reactions}

Epoxide polymerization. Before reaction, the catalysts were activated at $80{ }^{\circ} \mathrm{C}$ under vacuum overnight. Glass reaction vials were loaded with the catalyst (5 mol\% $\mathrm{Zn}$ ), 1,2-epoxyhexane ( $2 \mathrm{mmol}$ ) and diethyleneglycol (DEG, $0.2 \mathrm{mmol}$ ). The vials were then placed in an aluminum block at $110{ }^{\circ} \mathrm{C}$ and stirred at $500 \mathrm{rpm}$ using a magnetic stirring bar. After reaction, $2.5 \mathrm{~mL}$ of carbon disulfide were added, and the catalyst was recovered by centrifugation. The supernatant was collected in $10.00 \mathrm{~mm}$ quartz cells for near-infrared measurements performed on a Cary 5000 UV-VIS-NIR spectrophotometer. The epoxide conversion was determined by the absorbance of the sample at $2220 \mathrm{~nm}$, by correlating it to the concentration of 1,2-epoxyhexane remaining in the product mixture after reaction using a calibration curve. The TOF of the $\mathrm{Zn}$ sites was calculated as mol of epoxyhexane consumed per mol of $\mathrm{Zn}$ per hour.

Intermolecular hydroamination. Before reaction, the catalysts were activated at $80{ }^{\circ} \mathrm{C}$ under vacuum overnight. Glass reaction vials were loaded with the catalyst $(50 \mathrm{~mol} \% \mathrm{Zn}$ ), phenylacetylene $(0.5 \mathrm{mmol}), 4$-isopropylaniline $(1 \mathrm{mmol})$, tetradecane $(1 \mathrm{mmol})$ as internal standard and dry toluene $(1 \mathrm{~mL})$ as solvent. The vials were then placed in an aluminum block at $110{ }^{\circ} \mathrm{C}$ and stirred at $500 \mathrm{rpm}$ using a magnetic stirring bar. After reaction, the catalyst was recovered by centrifugation and the liquid supernatant was analyzed by GC (Shimadzu 2014 GC equipped with a FID detector and a CP-Sil 5 CB column) and GCMS (Agilent 6890 gas chromatograph, equipped with a HP-5MS column, coupled to a 5973 MSD mass spectrometer). After the reaction, the catalyst was dried under vacuum and characterized by PXRD. Recycling tests were performed after re-activation of the sample for $16 \mathrm{~h}$ before each run. The turnover frequency (TOF) of the $\mathrm{Zn}$ sites was calculated as mol of hydroamination product formed per mol of $\mathrm{Zn}$ per hour.

\section{Results and discussion}

\section{Structure solution and refinement}

The structure of the crystals grown using slow diffusion in a silica gel was solved by single crystal X-ray diffraction. While all non-H atoms could be found, the quality of the data was too low to allow satisfactory structure refinement. Through further synthesis optimization (vide infra), we were able to obtain a phase pure microcrystalline powder of the L-DMC. Synchrotron powder diffraction data were collected and successfully refined by the Rietveld method. Details of the crystallographic parameters of the final refinement are given in Table 1 and a Rietveld plot for the final cycles of refinement is presented in Fig. 1.

The structure crystallizes in the monoclinic space group $P 2_{1} / m$ and is shown in Fig. 2. The asymmetric unit consists of two symmetry independent $\mathrm{Zn}$ atoms and one Co atom, four cyanide groups (labelled $\mathrm{CN} 20$ to 23 , with each $\mathrm{C}$ and $\mathrm{N}$ atom numbered accordingly), acetate and three water molecules (represented as isolated O atoms Ow1, Ow11 and Ow12). Zn1 is tetrahedrally coordinated to three $\mathrm{N}$ atoms from two symmetry independent cyanide groups (twice to CN20 and once to CN21) and one $\mathrm{O}$ atom of the acetate $(\mathrm{O} 10)$. By contrast, $\mathrm{Zn} 2$ has an octahedral coordination environment consisting of three $\mathrm{N}$ atoms of two independent cyanide groups (twice CN22, once $\mathrm{CN} 23$ ), one $\mathrm{O}$ atom from an acetate group (O11) and two water molecules (Ow1). Co1 is also octahedrally coordinated by six C atoms, two from CN20 and CN22 and one from each of the other cyanide groups. The metal polyhedra are linked together through cyanide groups to form a puckered-layered structure in the $a b$-plane, in which two octahedrally coordinated Zn2 sites and one tetrahedral Zn1 site define a pocket, into which an octahedrally coordinated Zn2 from the underlying layer projects. The layers are coordinatively bonded together through an acetate group in the apical position of the tetrahedral Zn1, which bridges to the octahedral $\mathrm{Zn} 2$ in the layer below. Two capping water molecules (Ow1) project from this octahedral Zn2 site into the interstitial region where they form a H-bonding network with two further water molecules (Ow11 and Ow12), with $\mathrm{O} \cdots \mathrm{O}$ distances in the range $2.827(19)-3.054(16) \AA$.

It should be noted that the powder pattern reported by Zhang et al. ${ }^{53}$ of a DMC obtained by ball milling $\mathrm{K}_{3}\left[\mathrm{Fe}(\mathrm{CN})_{6}\right]$ and zinc acetate (complex 2 in ref. 53) is qualitatively similar to the diffraction pattern of L-DMC. We therefore suggest that the structure they observed during ball milling is an $\mathrm{Fe}(\mathrm{CN})_{6}$ analogue of our layered phase. Furthermore, from the FTIR spectrum of their complex 2, they found that acetate should be coordinated to $\mathrm{Zn}$, which is in agreement with our structure and FTIR analysis (vide infra).

Table 1 Summary of crystallographic results from Rietveld refinement of L-DMC

Composition
Space group (crystal system)
$a / \AA$
$b / \AA$
$c / \AA$
$\beta /{ }^{\circ}$
Cell volume $/ \AA^{3}$
$R_{\mathrm{wp}} / R_{\mathrm{Bragg}}$
$\chi^{2}$

$\mathrm{Co}(\mathrm{CN})_{6} \mathrm{Zn}_{2}\left(\mathrm{CH}_{3} \mathrm{COO}\right) \cdot 4 \mathrm{H}_{2} \mathrm{O}$ $P 2_{1} / m$ (monoclinic)

$12.3804(3)$

$7.50396(16)$

$8.4883(2)$

$85.3299(19)$

$785.97(4)$

$2.36 / 1.31$

0.652 


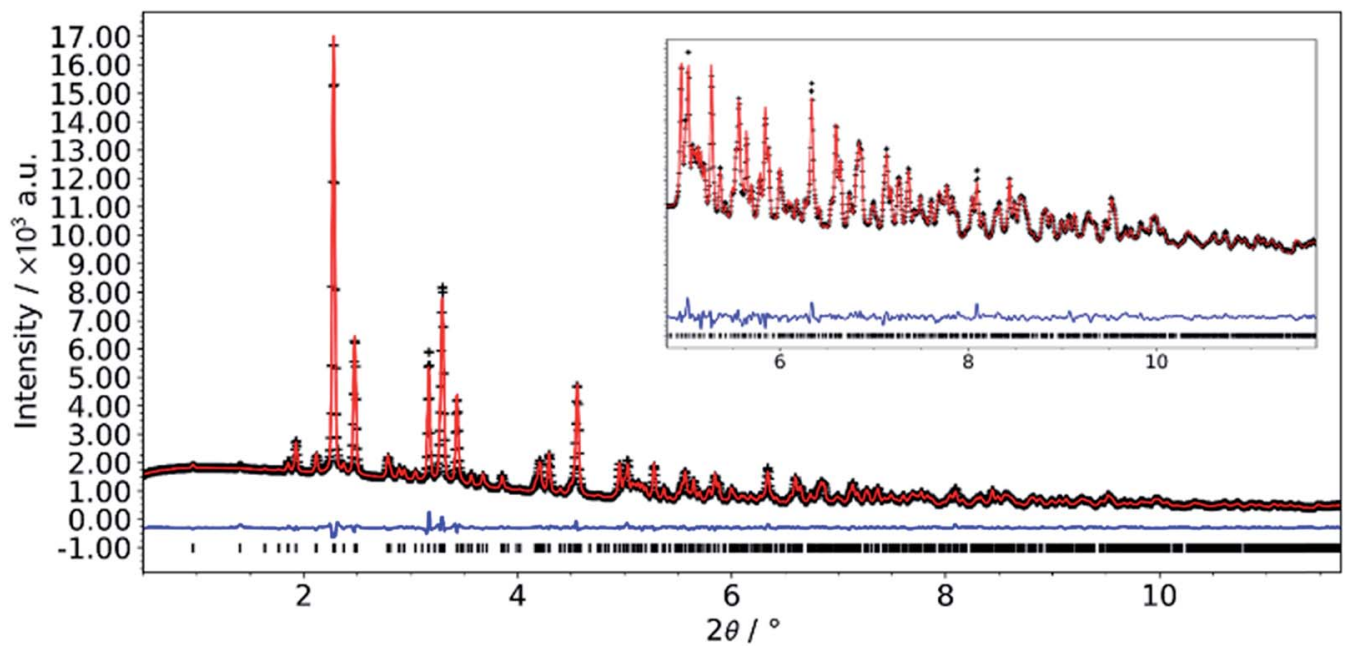

Fig. 1 Final Rietveld plot for the refinement of L-DMC. Data collected at beamline P02.1, PETRA III (DESY, Hamburg, Germany); $\lambda=0.20738 \AA$.

\section{Synthesis optimization}

To understand the formation mechanism of L-DMC, the single crystal synthesis conditions were modified and the structural changes were followed by high-throughput PXRD and both SEM and TEM (Table 2 and Fig. S1-S4†). To begin with, $\mathrm{ZnCl}_{2}-$ the most common zinc source in the synthesis of $\mathrm{Zn}_{3}\left[\mathrm{Co}(\mathrm{CN})_{6}\right]_{2}$ $\mathrm{DMCs}^{36}$ - was replaced by $\mathrm{Zn}\left(\mathrm{CH}_{3} \mathrm{COO}\right)_{2} \cdot 2 \mathrm{H}_{2} \mathrm{O}$. To favor slow crystal formation, the $\mathrm{Zn}\left(\mathrm{CH}_{3} \mathrm{COO}\right)_{2} \cdot 2 \mathrm{H}_{2} \mathrm{O}$ aqueous solution was cooled down using an ice bath. The resulting solid, DMC-1, exhibited a PXRD pattern (Fig. S1 $\dagger$ ) that resembled that of L-DMC. However, SEM images revealed the presence of two phases with different morphologies (Fig. S2 $\dagger$ ), which suggests that DMC-1 actually consists of a mixture of the cubic $(F m \overline{3} m)$ and the layered phase (monoclinic, $P 2_{1} / \mathrm{m}$ ). In an attempt to ensure the incorporation of acetate ions, the synthesis was repeated with $\mathrm{Zn}\left(\mathrm{CH}_{3} \mathrm{COO}\right)_{2} \cdot 2 \mathrm{H}_{2} \mathrm{O}$ dissolved in a $2 \mathrm{M}$ solution of acetic acid instead. This yielded a solid, DMC-2, that also consisted of a mixture of phases, as evidenced by its PXRD pattern and SEM images (Fig. S1 and S3†). When the concentration of the acetic acid solution was increased from $2 \mathrm{M}$ to $4 \mathrm{M}$, we obtained a solid (DMC-3) with a PXRD pattern very similar to that of L-DMC. Nevertheless, TEM images revealed that the synthesized solid was not phase pure (Fig. S4 $\dagger$ ), as two different morphologies (with two different metal ratios) were discerned. Only after increasing the crystallization temperature to $80{ }^{\circ} \mathrm{C}$, phase pure L-DMC was finally obtained. This synthesis temperature has also been used to crystallize a rhombohedral $\mathrm{Zn}_{3}\left[\mathrm{Co}(\mathrm{CN})_{6}\right]_{2}$ phase, in which all $\mathrm{Zn}$ atoms adopt a tetrahedral coordination. ${ }^{36,54}$ Additionally, we studied the effect of the presence of acetate ions during the synthesis. To that end, we replaced $\mathrm{Zn}\left(\mathrm{CH}_{3} \mathrm{COO}\right)_{2} \cdot 2 \mathrm{H}_{2} \mathrm{O}$ by other zinc salts, such as $\mathrm{ZnCl}_{2}$ and $\mathrm{Zn}\left(\mathrm{CF}_{3} \mathrm{COO}\right)_{2}$ while keeping the acetic acid concentration at $4 \mathrm{M}$ (DMC-4 and DMC-5, respectively). The pattern of DMC-4 exhibits reflections that are readily assigned to the rhombohedral phase, while the pattern of DMC-5 shows reflections typical of both a rhombohedral and a cubic structure. Substitution of acetic acid by trifluoroacetic acid (DMC-6) also produced a cubic DMC. These results indicate the importance of both the presence of acetic
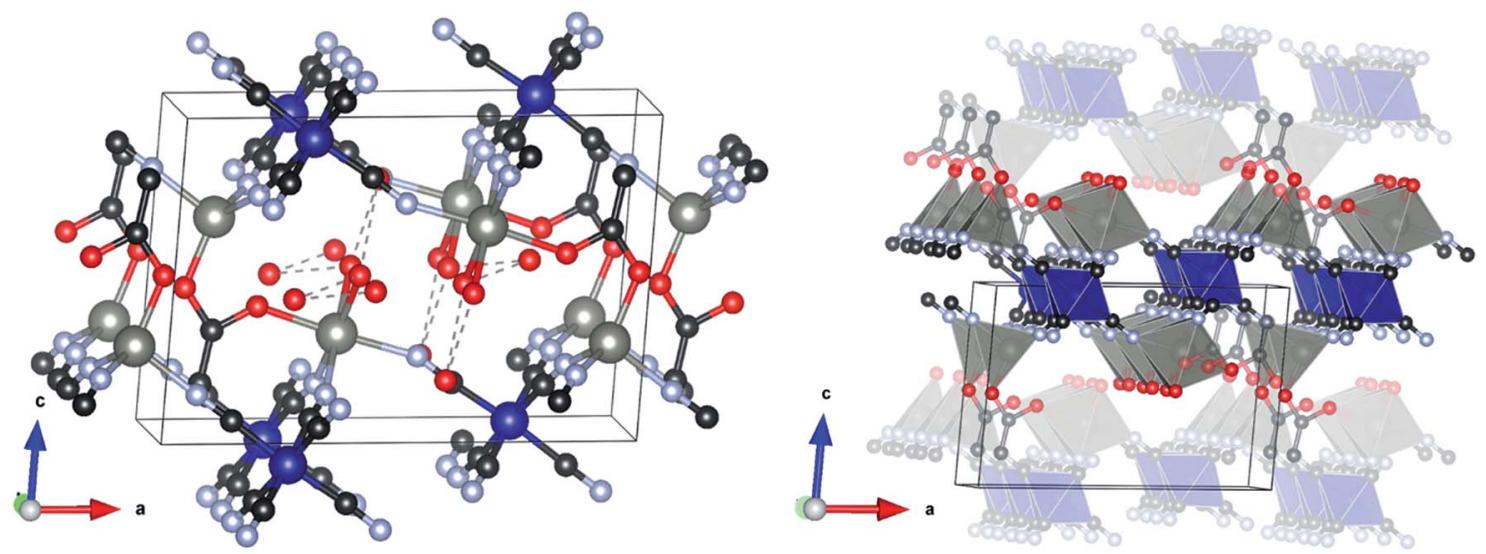

Fig. 2 Crystal structure of L-DMC (left) and polyhedral view showing the stacking of the layers in L-DMC (right). Red, blue, light grey, dark grey and black spheres represent $\mathrm{O}, \mathrm{N}, \mathrm{C}, \mathrm{Zn}$ and $\mathrm{Co}$ atoms, respectively. $\mathrm{H}$ atoms were omitted for clarity. 
Table 2 Overview of synthesis conditions of L-DMC and other synthesized DMC samples

\begin{tabular}{llll}
\hline & \multicolumn{2}{c}{ Synthesis conditions } & \\
\cline { 2 - 3 } $\begin{array}{l}\text { Sample } \\
\text { name }\end{array}$ & $\mathrm{Zn} \mathrm{source}$ & Crystallization temperature & Acid concentration \\
\hline L-DMC & $\mathrm{Zn}\left(\mathrm{CH}_{3} \mathrm{COO}\right)_{2} \cdot 2 \mathrm{H}_{2} \mathrm{O}$ & $80{ }^{\circ} \mathrm{C}$ & $4 \mathrm{M}^{a}$ \\
DMC-1 & $\mathrm{Zn}\left(\mathrm{CH}_{3} \mathrm{COO}\right)_{2} \cdot 2 \mathrm{H}_{2} \mathrm{O}$ & Ice bath & - \\
DMC-2 & $\mathrm{Zn}\left(\mathrm{CH}_{3} \mathrm{COO}\right)_{2} \cdot 2 \mathrm{H}_{2} \mathrm{O}$ & Ice bath & $2 \mathrm{M}^{a}$ \\
DMC-3 & $\mathrm{Zn}\left(\mathrm{CH}_{3} \mathrm{COO}\right)_{2} \cdot 2 \mathrm{H}_{2} \mathrm{O}$ & Ice bath & $4 \mathrm{M}^{a}$ \\
DMC-4 & $\mathrm{ZnCl}$ & $80^{\circ} \mathrm{C}$ & $4 \mathrm{M}^{a}$ \\
DMC-5 & $\mathrm{Zn}\left(\mathrm{CF}_{3} \mathrm{COO}\right)_{2}$ & $8{ }^{\circ} \mathrm{C}$ & $4 \mathrm{M}^{a}$ \\
DMC-6 & $\mathrm{Zn}\left(\mathrm{CH}_{3} \mathrm{COO}\right)_{2} \cdot 2 \mathrm{H}_{2} \mathrm{O}$ & Ice bath & $4 \mathrm{M}^{b}$ \\
${ }^{a}$ Acetic acid. ${ }^{b}$ Trifluoroacetic acid. & &
\end{tabular}

acid in the synthesis solution and the use of $\mathrm{Zn}\left(\mathrm{CH}_{3} \mathrm{COO}\right)_{2}$ $\cdot 2 \mathrm{H}_{2} \mathrm{O}$ as $\mathrm{Zn}$ source to form the desired layered structure, since the acetate ions are needed to balance the positive charge of the $\left\{\mathrm{Zn}_{2}\left[\mathrm{Co}(\mathrm{CN})_{6}\right]\right\}^{+}$layers and ensure their linkage. The other studied anions most likely do not have the appropriate geometry to form the desired 2D structure and incomplete hydrolysis of $\mathrm{Zn}$ acetate might be necessary to avoid formation of the cubic structure. Furthermore, the electronic properties of the anions, in all likelihood, also play a crucial role in the synthesis of the layered phase. In this sense, $\mathrm{CF}_{3} \mathrm{COO}^{-}$may bind too poorly to $\mathrm{Zn}$, as it offers low electron density, and thus it can be easily displaced by water, forming a cubic structure.

In an attempt to delaminate the layered structure, the optimized synthesis of L-DMC was slightly modified. Before final isolation (final washing step), the solid was dispersed in an aqueous miscible organic solvent (AMOS) for $16 \mathrm{~h} .{ }^{55}$ The structural changes that occurred during the AMOS dispersion procedure were followed by high throughput powder X-ray diffraction (Fig. S5 $\dagger$ ). No significant changes were observed in the patterns of L-DMC after washing with the solvents (acetone, methanol, ethanol, acetonitrile and acetaldehyde). This suggests that no exfoliation took place and that the L-DMC structure was maintain, confirming its chemical stability.

\section{Characterization}

From ICP-OES analysis of L-DMC, a $\mathrm{Zn}$ : Co molar ratio of 2.0 was obtained, which corresponds with the theoretical composition of L-DMC $-\mathrm{Zn}_{2}\left[\mathrm{Co}(\mathrm{CN})_{6}\right]\left(\mathrm{CH}_{3} \mathrm{COO}\right) \cdot 4 \mathrm{H}_{2} \mathrm{O}$. TEM images were collected at different regions to corroborate the phase purity of L-DMC (Fig. 3). All images show a flake-like morphology, typical of a two-dimensional (2D) geometry, with many of the flakes randomly aggregated. Moreover, HAADFSTEM images and EDX mapping of L-DMC (Fig. S6 $\dagger$ ) confirm a homogeneous distribution of $\mathrm{Zn}$ and Co throughout the structure with a $\mathrm{Zn}$ : Co molar ratio of 2.0. The FTIR spectra of L-DMC (Fig. S7†) exhibits all the bands associated with DMCs, ${ }^{54}$ as well as two additional bands around $1550 \mathrm{~cm}^{-1}$ and $1450 \mathrm{~cm}^{-1}$ attributed to the asymmetric and symmetric vibrations of $-\mathrm{COO}^{-}$, respectively. ${ }^{56-58}$ The presence of such bands in the FTIR spectra is in agreement with the solved crystal structure. Moreover, the band attributed to the stretching vibrations of the $\mathrm{C} \equiv \mathrm{N}$ bond is observed at $2190 \mathrm{~cm}^{-1}$, a red shift compared to the $\nu(\mathrm{C} \equiv \mathrm{N})$ frequency in the spectrum of cubic $\mathrm{Zn}_{3}\left[\mathrm{Co}(\mathrm{CN})_{6}\right]_{2}$ DMC complexes $\left(2200 \mathrm{~cm}^{-1}\right)$, indicating the influence of the acetate anions on the electronic environment of Zn. ${ }^{1} \mathrm{H}-{ }^{13} \mathrm{C}$ CPMAS NMR spectrum of L-DMC (Fig. 4) exhibits two well resolved signals of acetate at about 184 and $22 \mathrm{ppm}$ (belonging to carboxyl and methyl groups, respectively), and four partly overlapped signals between 125 and 140 ppm, which can be assigned to carbon nuclei of the four crystallographically distinct cyanide groups. This is in excellent agreement with the proposed structure of L-DMC. Note that signal intensities in the ${ }^{1} \mathrm{H}-{ }^{13} \mathrm{C}$ CPMAS NMR spectrum do not properly reflect the abundancies of individual species in the crystals, because the efficiency of polarization transfer from protons is very different to carbon nuclei within $-\mathrm{CH}_{3},-\mathrm{COO}^{-}$or $-\mathrm{CN}^{-}$groups. ${ }^{1} \mathrm{H}$ MAS NMR measurement (Fig. S8 $\dagger$ ) resolves a stronger signal of water molecules at $4.2 \mathrm{ppm}$ and a weaker signal of the $-\mathrm{CH}_{3}$ groups of acetate at $1.7 \mathrm{ppm}$, and thus additionally confirms that L-DMC comprises coordinating water molecules. TG-MS analysis of L-DMC (Fig. S9†) showed two marked mass decays: a first decay
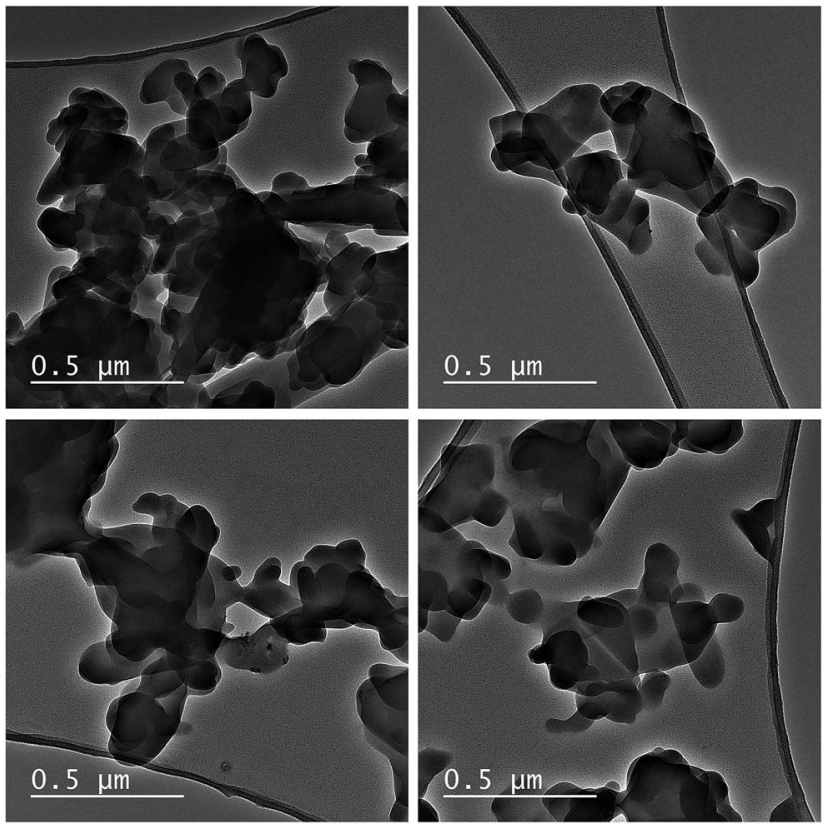

Fig. 3 TEM images of L-DMC. 


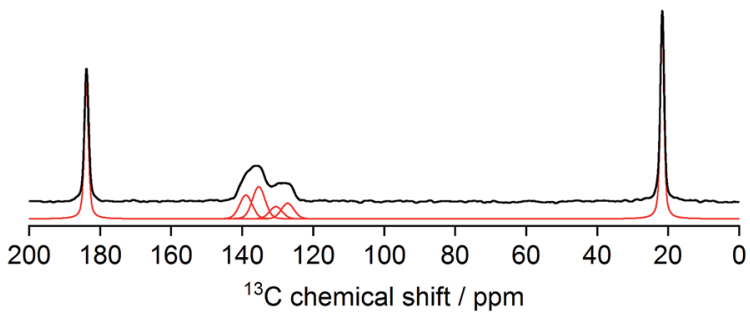

Fig. $4{ }^{1} \mathrm{H}-{ }^{13} \mathrm{C}$ CPMAS NMR spectrum of L-DMC (thick black line measured; thin red line - decomposition into individual contributions).

before $100{ }^{\circ} \mathrm{C}(\sim 10 \%$ mass loss $)$ attributed to the elimination of water, and a second decay between 320 and $390{ }^{\circ} \mathrm{C}(\sim 35 \%$ mass loss) corresponding to the decomposition of CN. Since the TGMS analysis was performed under air flow, the cyanide ligands were removed as $(\mathrm{CN})_{2}$, and the observed $\mathrm{CO}_{2}$ evolution indicates the decomposition of acetate as no acetic acid desorption was observed before this temperature. After the analysis, the recovered powder exhibited an intense green color, which is indicative of the formation of $\mathrm{Zn}_{1-x} \mathrm{Co}_{x} \mathrm{O}$ oxides (cobalt green). The $\mathrm{N}_{2}$ adsorption isotherm at $-196{ }^{\circ} \mathrm{C}$ of cubic $\mathrm{Zn}_{3}\left[\mathrm{Co}(\mathrm{CN})_{6}\right]_{2}$ DMCs is a Type I isotherm with no hysteresis loop, typical of purely microporous materials. In contrast, the isotherm of L-DMC, presented in Fig. S10, $\dagger$ shows a small hysteresis loop..$^{59,60}$ The high initial $\mathrm{N}_{2}$ uptake at low $p / p_{0}$ is attributed to the filling of micropores, while the slope in the 0.25 to 0.35 range indicates the presence of a considerable external surface area $\left(S_{\text {ext }}\right)$ in agreement with the small crystallite size and platelike morphology ${ }^{61}$ Analysis of the $\mathrm{N}_{2}$ sorption isotherm of L-DMC results in a BET surface area $\left(S_{\mathrm{BET}}\right)$ of $784 \mathrm{~m}^{2} \mathrm{~g}^{-1}$ and a $S_{\text {ext }}$ of $123 \mathrm{~m}^{2} \mathrm{~g}^{-1}$, which are both higher than those obtained for DMC-PTMEG (Table S1 $\dagger$ ). Furthermore, the MPSD was estimated from the Ar adsorption-desorption isotherms. Horvath-Kawazoe (HK) pore size analyses disclose differences in the microporous nature of both materials (Fig. S11†). While DMC-PTMEG exhibits a relatively narrow MPSD, centered around $6.7 \AA$, the MPSD of L-DMC shows the presence of three micropore systems with maxima around 6, 10 and $11 \AA$. This evidences the different geometries between L-DMC and the common, cubic DMC structure.

\section{Catalytic reactions}

The advantages of L-DMC over the benchmark DMC catalyst are evident in two important DMC applications: ring opening polymerization of 1,2-epoxyhexane and intermolecular hydroamination of phenylacetylene with 4-isopropylaniline. For the ring opening polymerization - one of the most important applications of $\mathrm{DMCs}^{62,63}$ - a significant increase in the 1,2epoxyhexane conversion is observed when L-DMC is employed as catalyst (Fig. 5, top). In fact, almost full conversion is achieved after only $0.5 \mathrm{~h}$ reaction time $(92 \%)$, which represents a vast improvement over the $61 \%$ conversion obtained with DMC-PTMEG. Furthermore, the initial TOF obtained with L-DMC is 1.5 higher than that obtained with DMC-PTMEG $\left(\mathrm{TOF}_{\mathrm{L}-\mathrm{DMC}}=6.2\right.$ and $\left.\mathrm{TOF}_{\mathrm{DMC}-\mathrm{PTMEG}}=4.1\right)$.
The second application, the hydroamination reaction, is a $100 \%$ atom efficient route towards the production of fine chemicals, ${ }^{64,65}$ thus representing a greener alternative over other important $\mathrm{C}-\mathrm{N}$ bond forming reactions, like the BuchwaldHartwig amination. Furthermore, the formation of undesired products is limited, as only acetophenone was formed as a side product under these reaction conditions. Zn-based Lewis acid DMCs have been found to be superior catalysts for this reaction, showing a higher selectivity to the hydroamination product than materials that contain Brønsted acid sites. ${ }^{6,7,65,66}$ Fig. 5 (bottom) shows the conversion of phenylacetylene and the yield of the desired hydroamination product obtained with DMC-PTMEG and L-DMC, and the kinetic data for L-DMC are presented in Fig. S12. $\dagger$ The higher catalytic activity of L-DMC $\left(\mathrm{TOF}_{\mathrm{L}-\mathrm{DMC}}=0.87\right.$ compared to $\left.\mathrm{TOF}_{\mathrm{DMC}-\mathrm{PTMEG}}=0.23\right)$ can be
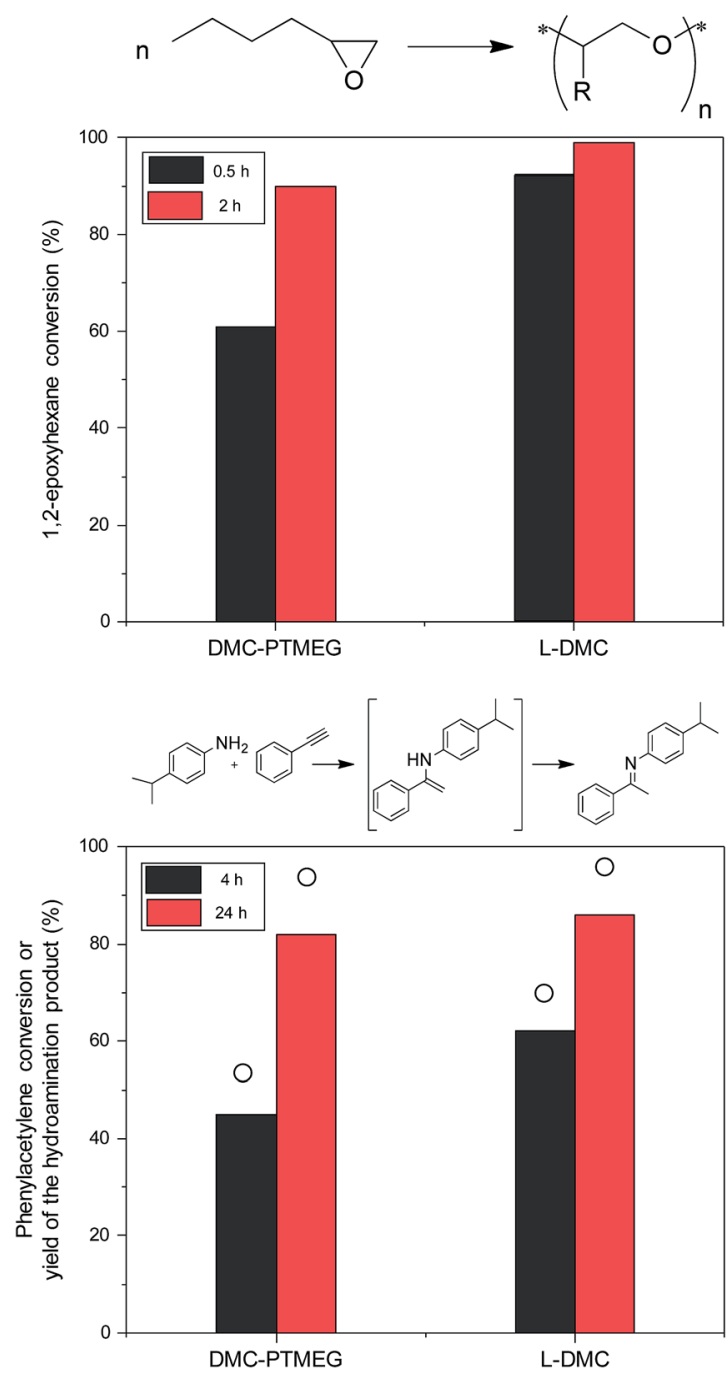

Fig. 5 Catalytic activity results for L-DMC and DMC-PTMEG. Top: Epoxide polymerization (reaction conditions: $2 \mathrm{mmol}$ of 1,2-epoxyhexane, $0.2 \mathrm{mmol}$ of DEG, $5 \mathrm{~mol} \% \mathrm{Zn}, 110^{\circ} \mathrm{C}$ ). Bottom: Intermolecular hydroamination. Circles represent phenylacetylene conversion and bars represent yield of the hydroamination product (reaction conditions: $0.5 \mathrm{mmol}$ of phenylacetylene, $1 \mathrm{mmol}$ of 4 -isopropylaniline, $1 \mathrm{~mL}$ of toluene, $1 \mathrm{mmol}$ of tetradecane, $50 \mathrm{~mol} \% \mathrm{Zn}, 110{ }^{\circ} \mathrm{C}$ ). 
attributed to a combination of the easier accessibility of the catalytic sites and the changed coordination environment of the $\mathrm{Zn}$ atoms in the structure. Additionally, the effect of the presence of acetate ions in the structure of L-DMC on its high catalytic activity cannot be disregarded, since it has been found to enhance the performance of DMC catalysts for other organic reactions. ${ }^{\mathbf{1 1}}$ Nevertheless, in order to fully disclose their involvement in the reaction mechanism, further studies are required.

As observed in both catalytic activity tests, the differences in activity exhibited by the DMCs highlight the advantages of L-DMC. The catalyst L-DMC also exhibits a higher hydroamination activity than the other synthesized DMCs and other Lewis acid catalysts (Tables $\mathrm{S} 2$ and $\mathrm{S} 3 \dagger$ ). Furthermore, recycling tests, PXRD and FTIR characterization after three hydroamination runs show the high stability and reusability of L-DMC as a solid catalyst (Fig. S13-S15 $\dagger$ ). The leaching of active species from the solid catalysts was studied by a hot filtration test (Fig. S16 ${ }^{\dagger}$ ). To this end, the catalyst was removed from the hot reaction mixture after $0.5 \mathrm{~h}$ reaction time (phenylacetylene conversion, $\sim 24 \%$ ). The clear supernatant (in the absence of solid catalysts) was allowed to react for an additional $19.5 \mathrm{~h}$ reaction time, after which no increase in phenylacetylene conversion was detected. This indicates that no leaching of catalytically active species from the solid occurs during the reaction under the studied conditions.

\section{Conclusions}

In summary, we have successfully synthesized and characterized a new 2D layered DMC phase, L-DMC, consisting of positively charged $\left\{\mathrm{Zn}_{2}\left[\mathrm{Co}(\mathrm{CN})_{6}\right]\right\}^{+}$layers connected through acetate anions. L-DMC was more active than the benchmark DMC catalyst in both the ring opening polymerization of 1,2-epoxyhexane and in the intermolecular hydroamination of phenylacetylene and 4-isopropylaniline. Furthermore, recycling, PXRD, FTIR and hot filtration tests demonstrated the good reusability and stability of L-DMC. This represents, to the best of our knowledge, the first two-dimensional DMC based on the catalytically active $\mathrm{Zn}$-Co metal combination. The successful synthesis and excellent catalytic properties of L-DMC may lead to new studies focused on exploring further modifications through, for instance, intercalation of other molecules or pillaring, in order to fine-tune its physicochemical properties.

\section{Conflicts of interest}

There are no conflicts to declare.

\section{Acknowledgements}

This project has received funding from the European Union's Horizon 2020 research and innovation programme under the Marie Sklodowska-Curie grant agreement No 641887 (project acronym: DEFNET). D. D. V. thanks KU Leuven for the Metusalem grant CASAS. F.W.O. Vlaanderen (Research Foundation Flanders) is thanked for project funding (D. D. V.: grant no.
G.07811.18N; C. V. G. and I. V.: grant no. G.0256.14N) and for a Postdoctoral Fellowship (T. D. B. \& B. B.). A. K. and G. M. acknowledge the financial support by the Slovenian Research Agency (research core funding No. P1-0021). Funding for the TEM through Hercules project AKUL/13/19 is kindly acknowledged. The authors are grateful to Prof. Jin Won Seo (KU Leuven) for TEM support, to Prof. Andrew L. Goodwin (Oxford) for the use of resources and discussions, to the beamline staff of I19 (Diamond Light Source, MT13639) for help and assistance, to Kwinten Janssens (KU Leuven) for the collection of additional FTIR data, and to Guangxia Fu and João Marreiros for $\mathrm{Ar}$ physisorption support.

\section{Notes and references}

1 J. Milgrom, US pat. 3278457A, 1966.

2 R. J. Belner, US pat. 3278458, 1966.

3 R. J. Herold, US pat. 3278459A, 1966.

4 Y. Dienes, W. Leitner, M. G. J. Muller, W. K. Offermans, T. Reier, A. Reinholdt, T. E. Weirich and T. E. Muller, Green Chem., 2012, 14, 1168-1177.

5 J. Langanke, A. Wolf, J. Hofmann, K. Bohm, M. A. Subhani, T. E. Muller, W. Leitner and C. Gurtler, Green Chem., 2014, 16, 1865-1870.

6 A. Peeters, P. Valvekens, F. Vermoortele, R. Ameloot, C. Kirschhock and D. De Vos, Chem. Commun., 2011, 47, 4114-4116.

7 A. Peeters, P. Valvekens, R. Ameloot, G. Sankar, C. E. A. Kirschhock and D. E. De Vos, ACS Catal., 2013, 3, 597-607.

8 C. Marquez, M. Rivera-Torrente, P. P. Paalanen, B. M. Weckhuysen, F. G. Cirujano, D. De Vos and T. De Baerdemaeker, J. Catal., 2017, 354, 92-99.

9 R. Srivastava, D. Srinivas and P. Ratnasamy, J. Catal., 2006, 241, 34-44.

10 C. Marquez, F. G. Cirujano, C. Van Goethem, I. Vankelecom, D. De Vos and T. De Baerdemaeker, Catal. Sci. Technol., 2018, 8, 2061-2065.

11 C. Marquez, F. G. Cirujano, S. Smolders, C. Van Goethem, I. Vankelecom, D. De Vos and T. De Baerdemaeker, Dalton Trans., 2019, 48, 3946-3954.

12 A. Ludi and H. U. Güdel, in Inorganic Chemistry. Structure and Bonding, Springer, Berlin, Heidelberg, 1973, pp. 1-21.

13 P. Valvekens and D. De Vos, in New Materials for Catalytic Applications, Elsevier, Amsterdam, 2016, pp. 1-12.

14 S. H. Byun, H. S. Seo, S. H. Lee, C.-S. Ha and I. Kim, Macromol. Res., 2007, 15, 393-395.

15 S. S. Kaye and J. R. Long, J. Am. Chem. Soc., 2005, 127, 65066507.

16 J. C. Wojdeł, S. T. Bromley, F. Illas and J. C. Jansen, J. Mol. Model., 2007, 13, 751-756.

17 J. Roque, E. Reguera, J. Balmaseda, J. Rodríguez-Hernández, L. Reguera and L. F. del Castillo, Microporous Mesoporous Mater., 2007, 103, 57-71.

18 N. J. Robertson, Z. Qin, G. C. Dallinger, E. B. Lobkovsky, S. Lee and G. W. Coates, Dalton Trans., 2006, 5390-5395. 
19 C. G. Silva, Y. Bouizi, V. Fornes and H. Garcia, J. Am. Chem. Soc., 2009, 131, 13833-13839.

20 F. Gándara, B. Gomez-Lor, E. Gutiérrez-Puebla, M. Iglesias, M. A. Monge, D. M. Proserpio and N. Snejko, Chem. Mater., 2008, 20, 72-76.

21 G. Fan, F. Li, D. G. Evans and X. Duan, Chem. Soc. Rev., 2014, 43, 7040-7066.

22 J. Helsen, J. Chem. Educ., 1982, 59, 1063-1065.

23 T. An, Y. Wang, J. Tang, Y. Wang, L. Zhang and G. Zheng, J. Colloid Interface Sci., 2015, 445, 320-325.

24 X. Liu, C. Shi, C. Zhai, M. Cheng, Q. Liu and G. Wang, ACS Appl. Mater. Interfaces, 2016, 8, 4585-4591.

25 Z.-H. Xuan, D.-S. Zhang, Z. Chang, T.-L. Hu and X.-H. Bu, Inorg. Chem., 2014, 53, 8985-8990.

26 M. K. Ram Reddy, Z. P. Xu, G. Q. (Max) Lu and J. C. Diniz da Costa, Ind. Eng. Chem. Res., 2006, 45, 7504-7509.

27 T. J. Pinnavaia, M.-S. Tzou, S. D. Landau and R. H. Raythatha, J. Mol. Catal., 1984, 27, 195-212.

28 K. Suzuki, T. Mori, K. Kawase, H. Sakami and S. Iida, Clays Clay Miner., 1988, 36, 147-152.

29 U. Díaz and A. Corma, Dalton Trans., 2014, 43, 10292-10316. 30 K. Varoon, X. Zhang, B. Elyassi, D. D. Brewer, M. Gettel, S. Kumar, J. A. Lee, S. Maheshwari, A. Mittal, C.-Y. Sung, M. Cococcioni, L. F. Francis, A. V. McCormick, K. A. Mkhoyan and M. Tsapatsis, Science, 2011, 334, 72-75.

31 A. Corma, V. Fornes, S. B. Pergher, Th. L. M. Maesen and J. G. Buglass, Nature, 1998, 396, 353-356.

32 A. Corma, U. Diaz, M. E. Domine and V. Fornés, Angew. Chem., 2000, 112, 1559-1561.

33 A. Corma, V. Fornés and U. Díaz, Chem. Commun., 2001, 2642-2643.

34 H. Liang, F. Meng, M. Cabán-Acevedo, L. Li, A. Forticaux, L. Xiu, Z. Wang and S. Jin, Nano Lett., 2015, 15, 1421-1427.

35 L. Li, R. Ma, Y. Ebina, N. Iyi and T. Sasaki, Chem. Mater., 2005, 17, 4386-4391.

36 J. Kuyper and G. Boxhoorn, J. Catal., 1987, 105, 163-174.

37 Y.-J. Huang, G. R. Qi and L. S. Chen, Appl. Catal., A, 2003, 240, 263-271.

38 I. Kim, K. Anas, S. Lee, C.-S. Ha and D.-W. Park, Catal. Today, 2008, 131, 541-547.

39 X.-H. Zhang, Z.-J. Hua, S. Chen, F. Liu, X.-K. Sun and G.-R. Qi, Appl. Catal., A, 2007, 325, 91-98.

40 Z. Blank, D. M. Speyer, W. Brenner and Y. Okamoto, Nature, 1967, 216, 1103-1104.

41 R. Z. LeGeros and J. P. LeGeros, J. Cryst. Growth, 1972, 13/14, 476-480.

42 I. Kim, J. T. Ahn, C.-S. Ha, C. S. Yang and I. Park, Polymer, 2003, 44, 3417-3428.

43 D. R. Allan, H. Nowell, S. A. Barnett, M. R. Warren, A. Wilcox, J. Christensen, L. K. Saunders, A. Peach, M. T. Hooper, L. Zaja, S. Patel, L. Cahill, R. Marshall, S. Trimnell,
A. J. Foster, T. Bates, S. Lay, M. A. Williams, P. V. Hathaway, G. Winter, M. Gerstel and R. W. Wooley, Crystals, 2017, 7, 336.

44 L. Palatinus and G. Chapuis, J. Appl. Crystallogr., 2007, 40, 786-790.

45 P. W. Betteridge, J. R. Carruthers, R. I. Cooper, K. Prout and D. J. Watkin, J. Appl. Crystallogr., 2003, 36, 1487.

46 O. V. Dolomanov, L. J. Bourhis, R. J. Gildea, J. A. K. Howard and H. Puschmann, J. Appl. Crystallogr., 2009, 42, 339-341.

47 A.-C. Dippel, H.-P. Liermann, J. T. Delitz, P. Walter, H. Schulte-Schrepping, O. H. Seeck and H. Franz, J. Synchrotron Radiat., 2015, 22, 675-687.

48 M. Basham, J. Filik, M. T. Wharmby, P. C. Y. Chang, B. El Kassaby, M. Gerring, J. Aishima, K. Levik, B. C. A. Pulford, I. Sikharulidze, D. Sneddon, M. Webber, S. S. Dhesi, F. Maccherozzi, O. Svensson, S. Brockhauser, G. Naray and A. W. Ashton, J. Synchrotron Radiat., 2015, 22, 853-858.

49 G. S. Pawley, Appl. Crystallogr., 1981, 14, 357-361.

50 H. M. Rietveld, J. Appl. Crystallogr., 1969, 2, 65-71.

51 A. A. Coelho, J. Appl. Crystallogr., 2018, 51, 210-218.

52 Y. Lee, S. Kim, J. K. Kang and S. M. Cohen, Chem. Commun., 2015, 51, 5735-5738.

53 W. Zhang, Q. Lin, Y. Cheng, L. Lu, B. Lin, L. Pan and N. Xu, J. Appl. Polym. Sci., 2012, 2, 977-985.

54 C. P. Krap, B. Zamora, L. Reguera and E. Reguera, Microporous Mesoporous Mater., 2009, 120, 414-420.

55 Q. Wang and D. O'Hare, Chem. Commun., 2013, 49, 63016303.

56 E. A. Secco and G. G. Worth, Can. J. Chem., 1987, 65, 25042508.

57 N. Masciocchi, E. Corradi, A. Sironi, G. Moretti, G. Minelli and P. J. Porta, Solid State Chem., 1997, 131, 252-262.

58 D. C. Pereira, D. L. A. de Faria and V. R. L. Constantino, J. Braz. Chem. Soc., 2006, 17, 1651-1657.

59 M. Thommes, K. Kaneko, A. V. Neimark, J. P. Olivier, F. Rodriguez-Reinoso, J. Rouquerol and K. S. W. Sing, Pure Appl. Chem., 2015, 87, 1051-1069.

60 A. Gil, S. A. Korili and M. A. Vicente, Catal. Rev.: Sci. Eng., 2008, 50, 153-221.

61 W. J. Roth, B. Gil, W. Makowski, B. Marszalek and P. Eliasova, Chem. Soc. Rev., 2016, 45, 3400-3438.

62 G. Trott, P. K. Saini and C. K. Williams, Philos. Trans. R. Soc., A, 2016, 374, 20150085.

63 S. Lee, S. T. Baek, K. Anas, C.-S. Ha, D.-W. Park, J. W. Lee and I. Kim, Polymer, 2007, 48, 4361-4367.

64 T. E. Müller, K. C. Hultzsch, M. Yus, F. Foubelo and M. Tada, Chem. Rev., 2008, 108, 3795-3892.

65 J. Penzien, T. E. Müller and J. A. Lercher, Microporous Mesoporous Mater., 2001, 48, 285-291.

66 J. C. Penzien, C. Haessner, A. Jentys, K. Kohler, T. E. Muller and J. A. Lercher, J. Catal., 2004, 221, 302-312. 